\title{
Evolution of ice crystal microstructure during creep experiments
}

\author{
Ilka HAMANN, ${ }^{1,2}$ Christian WEIKUSAT, ${ }^{1 *}$ Nobuhiko AZUMA, ${ }^{1}$ Sepp KIPFSTUHL ${ }^{2}$ \\ ${ }^{1}$ Department of Mechanical Engineering, Nagaoka University of Technology, 1603 Kamitomioka, \\ Nagaoka 940-2188, Niigata, Japan \\ ${ }^{2}$ Alfred Wegener Institute for Polar and Marine Research, Columbusstrasse, D-27568 Bremerhaven, Germany \\ E-mail: ilka.hamann@awi.de
}

\begin{abstract}
Results of laboratory uniaxial compression tests over the stress range 0.18-0.52 MPa and the strain range $0.5-8.6 \%$ at approximately -5 and $-20^{\circ} \mathrm{C}$ are presented. Grain-size analysis and comparisons with annealing tests confirm that grain-growth reducing processes are active during deformation. Microstructural observations reveal that subgrain-rotation recrystallization and grainshape changes due to strain-induced grain-boundary migration are the causes of the grain-growth deceleration. Further results from microstructural observations show that obstacle formation by dislocation walls and subgrain boundaries is the reason for isotropic hardening during creep. Subgrainboundary types that are likely to be relevant for studies on the activity of different dislocation types are described.
\end{abstract}

\section{INTRODUCTION}

The study of deformation mechanisms and their links to the crystal texture evolution of polycrystalline ice is of growing interest, as knowledge of the mechanical properties of ice in polar ice sheets is vitally important for the interpretation of ice-core records and modelling ice-sheet flow.

The flow of polycrystalline ice has been studied for many decades. Creep experiments on ice produce creep curves showing the primary, secondary and tertiary stages typical for many polycrystalline materials (e.g. Budd and Jacka, 1989; Paterson, 1994; Petrenko and Whitworth, 1999; Hooke, 2005). Processes which control the plasticity of ice in the different creep stages were reviewed by Duval and others (1983) using classical strain test parameters which describe the reaction of a test specimen to deformation. Although tertiary creep is more significant in glaciology (e.g. Budd and Jacka, 1989; Paterson, 1994; Petrenko and Whitworth, 1999), Glen's law describing the strain-ratestress relation in secondary creep (Glen, 1955) is widely applied in glacier studies. This secondary creep stage attracted particular interest because it is identified as a unique point on the ice creep curve (Jacka, 1984). The strain test parameters are not easy to obtain in ice sheets. However, as ice is a highly anisotropic material, due to its hexagonal crystal system, various processes (e.g. dislocation climb and glide and diffusional processes) compete during deformation. These processes act on the atomic scale and are therefore difficult to observe directly in deforming polycrystalline samples. Nonetheless, they leave behind certain structures on the grain and subgrain scale indicating deformation mechanisms, so microstructures can be used to study these processes. Single mechanisms, such as grain rotation or grain-boundary sliding, can be observed by studying the evolution of $c$ axes (e.g. Azuma and Higashi, 1985), grain size (e.g. Goldsby and Kohlstedt, 1997) and other microstructural properties. Recently, high-resolution crystallographic analysis has provided new information that

*Present address: Institute of Mineralogy, Ruprecht-Karls-University of Heidelberg, Im Neuenheimer Feld 236, D-69120 Heidelberg, Germany. improves our understanding of recrystallization processes (Montagnat and others, 2003; Miyamoto and others, 2005; Obbard and others, 2006b). For statistical observations at high spatial resolution, a new microstructure-mapping method (Kipfstuhl and others, 2006) allows more direct and easily obtainable observations of features produced by the deformation-related processes. In the future, comparing data obtained using this method for ice-core samples, with unknown deformation conditions, with data obtained in the same way for experimentally deformed ice, with wellknown deformation conditions, may add to our understanding of flow laws in ice sheets.

One important aspect of the structures of polycrystalline ice is the grain-size evolution. It is well established that the temperature-dependent normal grain growth with time (e.g. Gow, 1969) can be disturbed in natural ice (e.g. Gow and Williamson, 1976; Duval and Lorius, 1980; Thorsteinsson and others, 1995). Explanations for this grain-growth reduction have been discussed for many years (e.g. Gow and Williamson, 1976; Duval and Gac, 1980; Paterson, 1994), but there is, as yet, no consistent understanding to be found in the literature. In laboratory ice deformation experiments Jacka and Li (1994) found a steady-state crystal size with the tertiary creep stage. Examination of microstructures can help to understand the physical processes leading to grain-growth reduction and to evaluate whether these processes could be the cause of grain-size variations in ice sheets.

This work presents, for the first time, laboratory experimental studies on microstructural features that are clearly related to deformation. The aim is to give evidence for, and discuss processes leading to, the grain-growth reducing effect of deformation indicated by microstructural observations. These studies are used to clarify the processes leading to strain hardening during primary creep.

\section{METHODS}

\section{Experimental procedures}

In order to obtain bubble-free samples with a small grain size and without initial deformation features, samples were 
Table 1. Overview of the experimental conditions. Test samples were cylindrical with diameter 13-19 mm and length 14-38 mm. Temperatures are means over the duration of the experiment. In some cases it is not clear whether final strain rate is the minimum strain rate

\begin{tabular}{|c|c|c|c|c|c|c|c|c|}
\hline Experiment & $\begin{array}{c}\mathrm{T} \\
{ }^{\circ} \mathrm{C}\end{array}$ & $\begin{array}{l}\text { Stress } \\
\mathrm{MPa}\end{array}$ & $\begin{array}{l}\text { Approx. time } \\
\text { days }\end{array}$ & $\begin{array}{c}\text { Strain } \\
\%\end{array}$ & $\begin{array}{c}\text { Final strain rate } \\
\qquad \mathrm{s}^{-1}\end{array}$ & $\begin{array}{l}\text { Min. strain rate } \\
\mathrm{s}^{-1}\end{array}$ & $\begin{array}{c}\text { Mean grain size } \\
\mathrm{mm}^{2}\end{array}$ & $\begin{array}{l}\text { Mean initial grain size } \\
\qquad \mathrm{mm}^{2}\end{array}$ \\
\hline $4-5$ & -4.5 & 0.16 & 8 & 0.45 & $2.34 \times 10^{-9}$ & & 3.98 & 0.12 \\
\hline $5-5$ & -4.5 & 0.35 & 10 & 2.8 & $2.08 \times 10^{-8}$ & & 2.93 & 0.29 \\
\hline 6 & -4.5 & 0.35 & 3 & 1.7 & $4.11 \times 10^{-8}$ & & 2.25 & 0.59 \\
\hline 7 & -4.2 & 0.35 & 25 & 5.5 & $1.91 \times 10^{-8}$ & & 10.98 & 0.85 \\
\hline 9 & -4.7 & 0.35 & 1.5 & 0.51 & $2.04 \times 10^{-8}$ & & 1.07 & 0.27 \\
\hline 10 & -4.8 & 0.35 & 3 & 1.22 & $2.06 \times 10^{-8}$ & & 2.04 & 0.14 \\
\hline 11 & -4.9 & 0.35 & 0.5 & 0.44 & $2.38 \times 10^{-8}$ & & 1.48 & 0.25 \\
\hline 12 & -4.7 & 0.18 & 13 & 1.04 & $4.29 \times 10^{-9}$ & & 3.45 & 0.22 \\
\hline 14 & -4.9 & 0.52 & 3 & 3.58 & $8.66 \times 10^{-8}$ & $6.24 \times 10^{-8}$ & 1.43 & 0.08 \\
\hline 15 & -4.8 & 0.52 & 8 & 8.56 & $9.01 \times 10^{-8}$ & $8.58 \times 10^{-8}$ & 1.31 & 0.20 \\
\hline $4-23$ & -23.5 & 0.20 & 10 & 0.51 & $1.43 \times 10^{-9}$ & & 0.07 & 0.08 \\
\hline $5-23$ & -23 & 0.35 & 35 & 1.38 & $2.29 \times 10^{-9}$ & & 1.31 & 0.28 \\
\hline 8 & -23 & 0.35 & 28 & 1 & $1.10 \times 10^{-9}$ & & 0.65 & 0.27 \\
\hline 13 & -22.5 & 0.52 & 31 & 1.12 & $2.34 \times 10^{-9}$ & & 0.85 & 0.18 \\
\hline
\end{tabular}

produced using large-grained bubble-free ice obtained by slow freezing of pure water under vibration that were then exposed to a phase transition at $\sim 300 \mathrm{MPa}, \sim 233 \mathrm{~K}$. This procedure enables us to produce small-volume samples (cylindrical: $\sim 15-20 \mathrm{~mm}$ diameter, $\sim 50 \mathrm{~mm}$ length) with small grain sizes (mean diameter $\sim 0.6 \mathrm{~mm}$ ) due to nucleation/recrystallization processes during the phase change from ice II to ice Ih. In contrast to standard sample production procedures, which usually include pressure sintering, our samples are bubble-free, and do not exhibit deformational microstructures.

Samples were rounded using a lathe. Top and bottom surfaces were cut parallel with a microtome (cylindrical: 13-19 mm diameter, and $14-38 \mathrm{~mm}$ length). The creep machines we used consist of a basal plate, which is situated in a silicon oil bath and a loading stage lead by vertical guide rails. The silicon oil bath is used to prevent the deforming sample from sublimation and to keep the temperature constant during the test. A displacement sensor is attached to the loading stage, which moves down as the sample is compressed, and measures the shortening of the sample. Table 1 gives an overview of all experiments conducted during the study.

For reference, concurrent annealing of a small section cut from the initial samples was conducted in the same silicon oil bath used for creep experiments.

\section{Observation methods}

Thin sections were prepared according to standard procedures, allowing the surfaces to sublimate and reveal (sub)grain boundaries as etch grooves (Kipfstuhl and others, 2006). For each sample, at least two sections, one cut horizontally and the other vertically, were prepared. Microstructures were mapped afterwards with a manual $X Y$-stage and a differential interference microscope (Olympus $\mathrm{B} \times 51$ differential interference contrast (DIC), 10× lens). Two to six sectors ( $\sim 5 \mathrm{~mm}$ by $6 \mathrm{~mm}$ ) of each section, usually chosen close to the centre of the sample and not disturbed by, for example, bad sublimation regions, were photographed with $\sim 25$ images to get a representative overview of the sample. Grain size and shape were determined from overview pictures of the whole sample between crossed polarizers (Stereoscope $12,6 \times$ to $64 \times, 1 \times$ objective).

\section{Measurement methods}

Subgrain-boundary statistics were obtained from photomicrographs using digital image analysis. Microstructure maps were assembled from microscopic mosaic images and used to measure total subgrain-boundary length in the grain assemblage presented in the map. This had to be done manually, as subgrain boundaries, in contrast to grain boundaries, appear only as thin faint lines in the images which are difficult to extract automatically. The area of the microstructure map was measured and the subgrainboundary density calculated. Subgrain-boundary density is defined as the sum of all subgrain-boundary lengths per area. Possible interrelations between subgrain-boundary density and the sample cutting scheme (i.e. horizontally or vertically cut) were investigated by systematically changing cutting schemes. These types of observations have not been reported before; this may be because, apart from the timeconsuming measurements and analysis processes, standard sample production procedures include pre-deformation due to non-hydrostatic pressure (e.g. Jacka and Lile, 1984; Goldsby and Kohlstedt, 1997) which means deformation microstructures are present in initial samples. Our samples have no such initial deformation features.

Grain parameters were derived from crossed-polarizer pictures which were segmented using an edge filter, revealing the basic network of grain boundaries (Gay and Weiss, 1999). Artefacts were removed manually. The grainboundary network pictures were analyzed with imageprocessing software to obtain grain-size (area, perimeter) data by pixel counting. The software assumes an ellipse of the same area as each grain. Using the length of the major and minor axes of this ellipse, grain-elongation data and the aspect ratio of each grain can be derived.

The ratio of convex perimeter to real perimeter (Fig. 1) called 'perimeter ratio' has been adopted to describe the morphology of the grains. This parameter, used here for the first time to describe the grain shape in polycrystalline ice, 

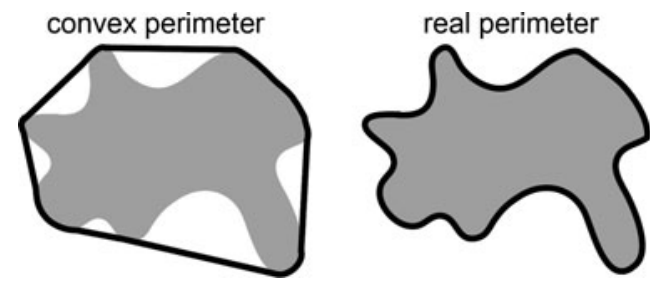

Fig. 1. Schematic illustration of the definition of convex perimeter and real perimeter measured by Image-Pro. The ratio is used as a measure of the irregularity of grains.

can be measured using Image-Pro Plus (Media Cybernetics). It was used in a similar way to measure the roughness of grains in unbound aggregates of gneiss forming a base course in road surfaces. A grain with straight boundaries has a perimeter ratio of 1 ; the value decreases as the irregularity becomes more complex.

\section{EXPERIMENTAL RESULTS}

This study combines observations of creep, in terms of displacement, strain and strain rate, with observations of the microstructure of the sample before and after deformation. The microstructure observations are focused on grain size, grain shape and subgrain-boundary evolution with time and creep. As the total strains were low, most samples did not appear to be macroscopically deformed - they did not show macroscopic strain localization such as bending of the whole sample or cracking.

\section{Creep data}

Experiments were conducted to reach strains of $0.4-8.6 \%$ at $\sim-5^{\circ} \mathrm{C}$ and $0.5-1.4 \%$ at $\sim-23^{\circ} \mathrm{C}$. Greater strains were not attempted as the apparatus was only available for a limited time. Only two of the experiments clearly reached minimum isotropic creep. In the highest-strain experiments, strain rate usually stopped decreasing at $\sim 1-2 \%$ strain (Fig. 2).

\section{Grain-size data}

Mean grain size increased during almost all our creep tests (Table 1). Comparisons with data derived from grain-growth experiments at $-5^{\circ} \mathrm{C}$ (Nishimura, 2004) using the same sample type, produced by phase transition, indicate significantly faster increases in grain size when no stress is applied (Fig. 3). A striking difference was found between samples deformed at $\sim-5^{\circ} \mathrm{C}$ and at $\sim-23^{\circ} \mathrm{C}$ (Fig. 3).

\section{Grain-shape data}

Elongation, and therefore mean grain aspect ratio, slightly increases with increasing strain (Fig. 4a). At the highest strains a steady aspect ratio of $\sim 1.7$ was reached. Importantly, no difference in mean grain aspect ratio could be found between vertically and horizontally cut sections. The orientation of the majority of the grain elongations does not change significantly and no preferred grain-elongation direction could be observed.

We also investigated the detailed irregularity of the grains. Polygonal and regular-shaped grains, isometric with straight grain boundaries and triple-junction angles close to $120^{\circ}$, were observed in samples before deformation and in samples which had been annealed (Fig. 5a). Deformed samples show irregular grains with bulging and curved grain boundaries,

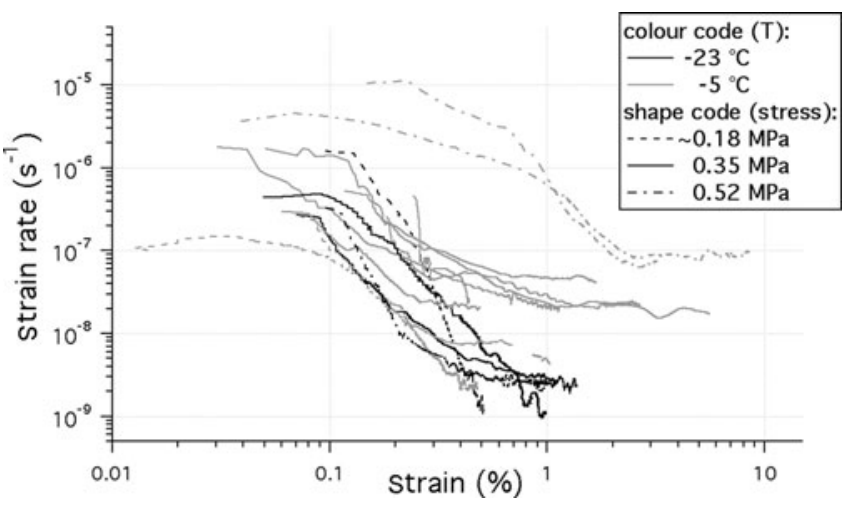

Fig. 2. Strain rate vs strain for all experiments.

extending into neighbouring grains to produce an interlocking texture (Fig. 5b). With increasing strain the grains become increasingly irregular. Perimeter ratio values slightly below 1 are obtained for the highly regular grains in initial and annealed samples. With increasing strain the increasing bulging of the grain boundaries and increasing localized curvature radii decrease the perimeter ratio (Fig. 4b).

\section{Subgrain boundaries and subgrain-boundary density}

Kipfstuhl and others (2006) showed that subgrain boundaries are revealed as grooves under controlled sublimation conditions. The dependence of sublimation/thermal grooving on misorientation was described generally by Mullins (1957) and by Saylor and Rohrer (1999) for ceramic polycrystals. Recently Obbard and others (2006a) described a model for preferred sublimation and some special aspects of grain-boundary grooving for ice. As the transition from subgrain boundaries to grain boundaries is gradual, a clear definition or critical value to distinguish between the two is difficult. In materials science the transition is typically taken as between $10^{\circ}$ and $15^{\circ}$ (see, e.g., Humphreys and Hatherly, 2004, p. 92) and in geology as $<5^{\circ}$ (see, e.g., Passchier and Trouw, 1996, p. 265). For ice, Montagnat and Duval (2000) used $5^{\circ}$ as the critical value for the transformation. Preliminary results of $\mathrm{X}$-ray Laue diffractometry (personal communication from A. Miyamoto, 2007) reveal typical misorientations for strong grooves of $\sim 3^{\circ}$. Faint sublimation grooves, although clearly visible, cannot be easily detected by $\mathrm{X}$-ray measurements, indicating a very small misorientation $\left(\ll 0.5^{\circ}\right)$. Therefore it is probably correct to call some

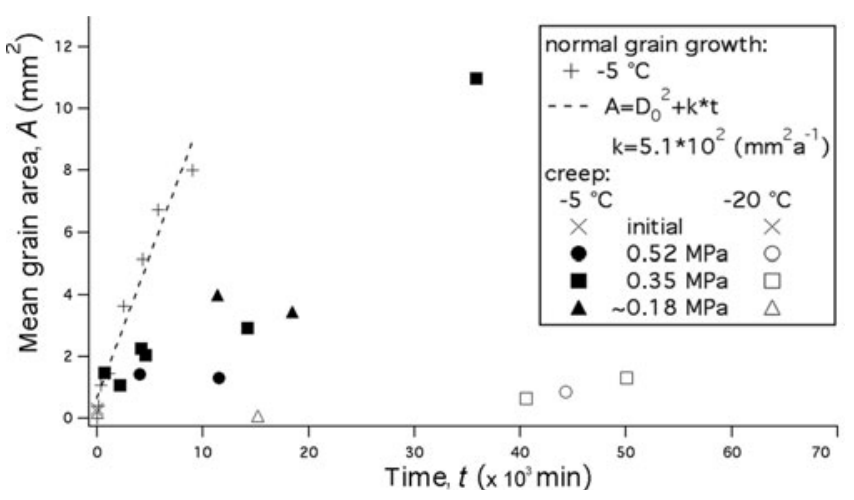

Fig. 3. Grain-size evolution during creep tests and Nishimura's (2004) grain-growth experiment. 


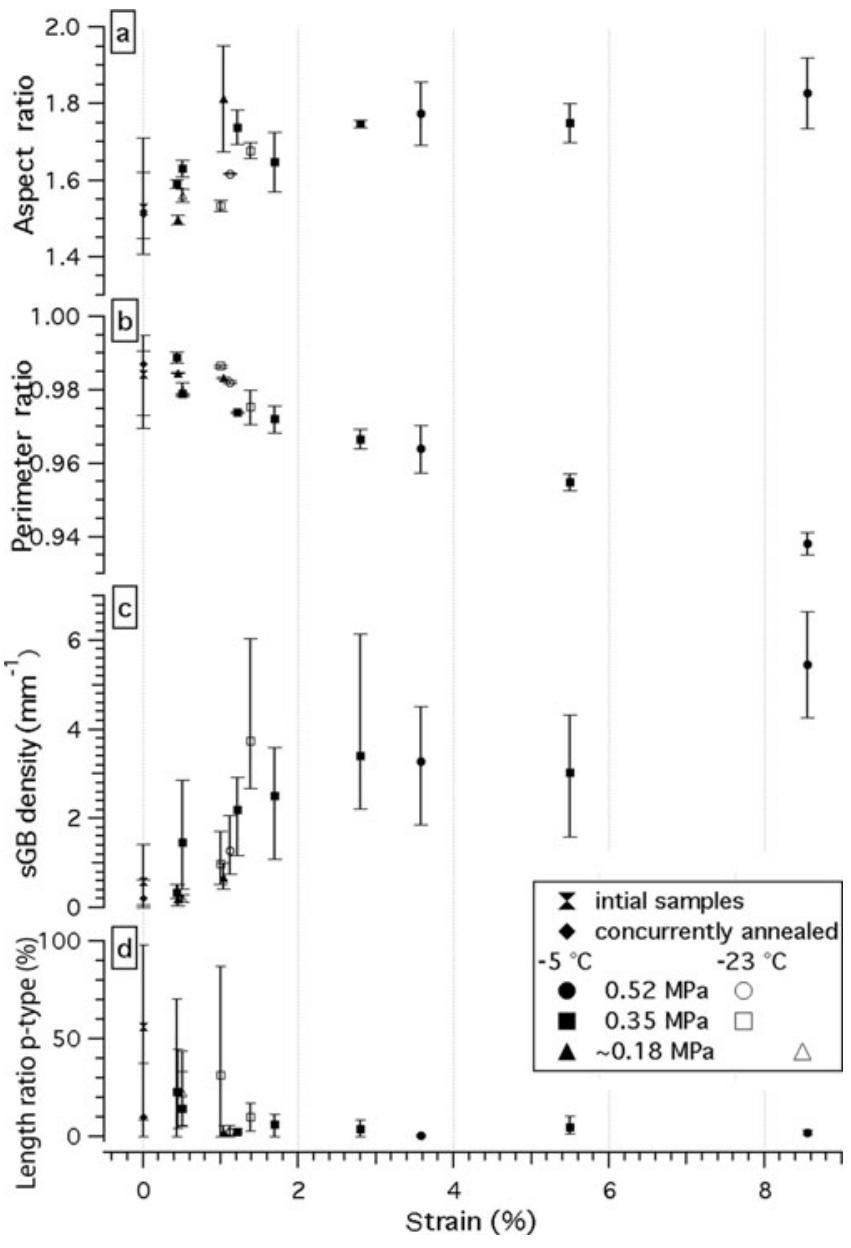

Fig. 4. Microstructural evolution in creep experiments with increasing strain. $(a, b)$ Grain aspect ratio (a); grain perimeter ratio (see Fig. 1 and text for definition) (b). Mean derived from vertical and horizontal sections. (c, d) Subgrain-boundary (sGB) density (c); frequency of parallel-type subgrain boundaries (ratio of the total length of parallel-type subgrain boundaries to total length of all subgrain boundaries) (d). Mean over four to six selected regions (area: $\sim 5 \mathrm{~mm} \times \sim 6 \mathrm{~mm}$ ) in a section. Bars indicate variability.

of these sublimation grooves dislocation walls rather than subgrain boundaries. The distinction is not made here, because of the gradual transition from dislocation walls to subgrain boundaries to grain boundaries. High-resolution misorientation measurements can be performed using hard X-ray equipment (Montagnat and others, 2003), useful for
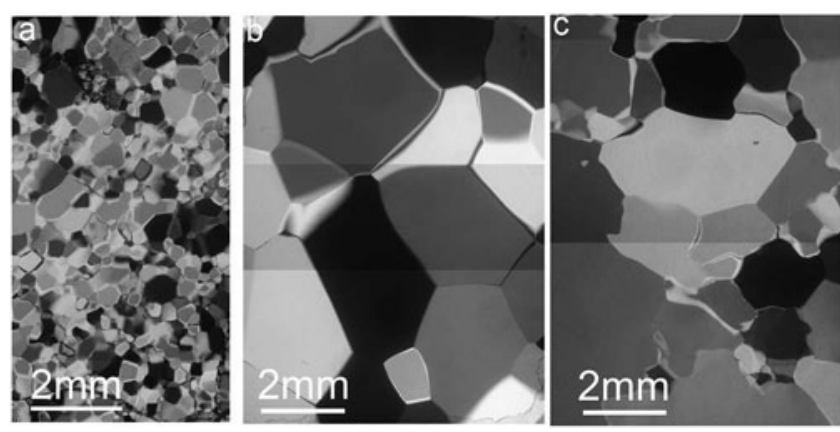

Fig. 5. Composite photomicrographs taken between crossed polarizers. (a) Initial sample. (b, c) After 3 days at $-4.9^{\circ} \mathrm{C}$ : annealing only (b); creep test at $0.52 \mathrm{MPa}$ and $3.58 \%$ total strain (c).

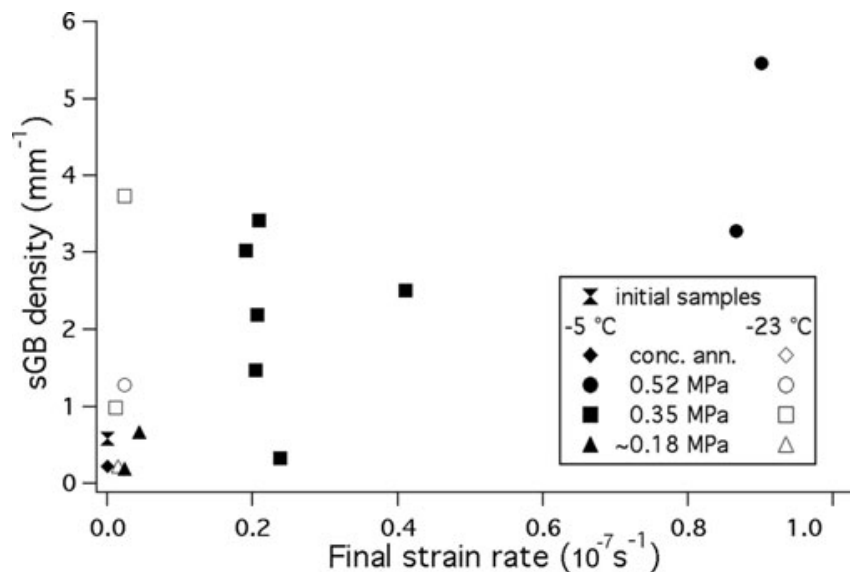

Fig. 6. Mean subgrain-boundary density against final strain rate. Mean over four to six selected regions (area: $\sim 5 \mathrm{~mm} \times 6 \mathrm{~mm}$ ) in a section. Further experiments are required.

distinguishing these features, but the sample sizes are tiny and neither geometric arrangement nor statistics on substructures can be obtained.

The systematic study of subgrain-boundary density during creep tests reveals it evolves with strain (Fig. 4c). Mean subgrain-boundary density increases with strain (Fig. 4c) from $\sim 0.5 \%$ up to $\sim 2 \%$. For strains larger than $2-3 \%$ the increase stops at a value of $\sim 3.5 \mathrm{~mm}^{-1}$. No systematic difference in subgrain-boundary density or grain size was observed between horizontally and vertically cut sections. Values plotted in Figure 4c are mean values of at least four individual measurements, each determined for one microstructure map ( $\sim 5 \mathrm{~mm} \times 6 \mathrm{~mm}$ of a sample surface). Particularly for strains higher than $1 \%$, the individual measurements have a large scatter (bars in Fig. 4c), reflecting a heterogeneous distribution of deformation over the section. Figure 4c shows that the range of variability is approximately similar in all samples, $\sim 3 \mathrm{~mm}^{-1}$ above $1 \%$ strain, which indicates that our analysis of four microstructure maps is representative. As experiments at lower temperatures take much longer, only a few data are so far available, though these agree well with the above finding.

Figure 6 illustrates the subgrain-boundary density with final strain rates measured for the experiments. Although a clear correlation cannot yet be shown, subgrain-boundary density seems to increase with strain rate. Further experiments are required to investigate the relation between subgrain evolution and strain rate.

\section{Subgrain-boundary types}

Different subgrain-boundary types classified by shape, and very similar to those found in Antarctic ice (data will be presented elsewhere), have been observed. The appearance of subgrain boundaries is manifold (Fig. 7). Variations occur in shape and intensity (i.e. greyscale value). The subgrainboundary shapes vary from regular straight (rare) to regular bowed (often) and irregular zigzag or step-shaped (very often). The latter sometimes build conspicuous networks. Straight, exactly parallel groups of subgrain boundaries are striking, often appearing faint and light grey.

The shapes of subgrain boundaries have been investigated with respect to crystal orientation using a combination of microstructure mapping and etch-pit analysis (Fig. 8), which enables a more definite classification of 


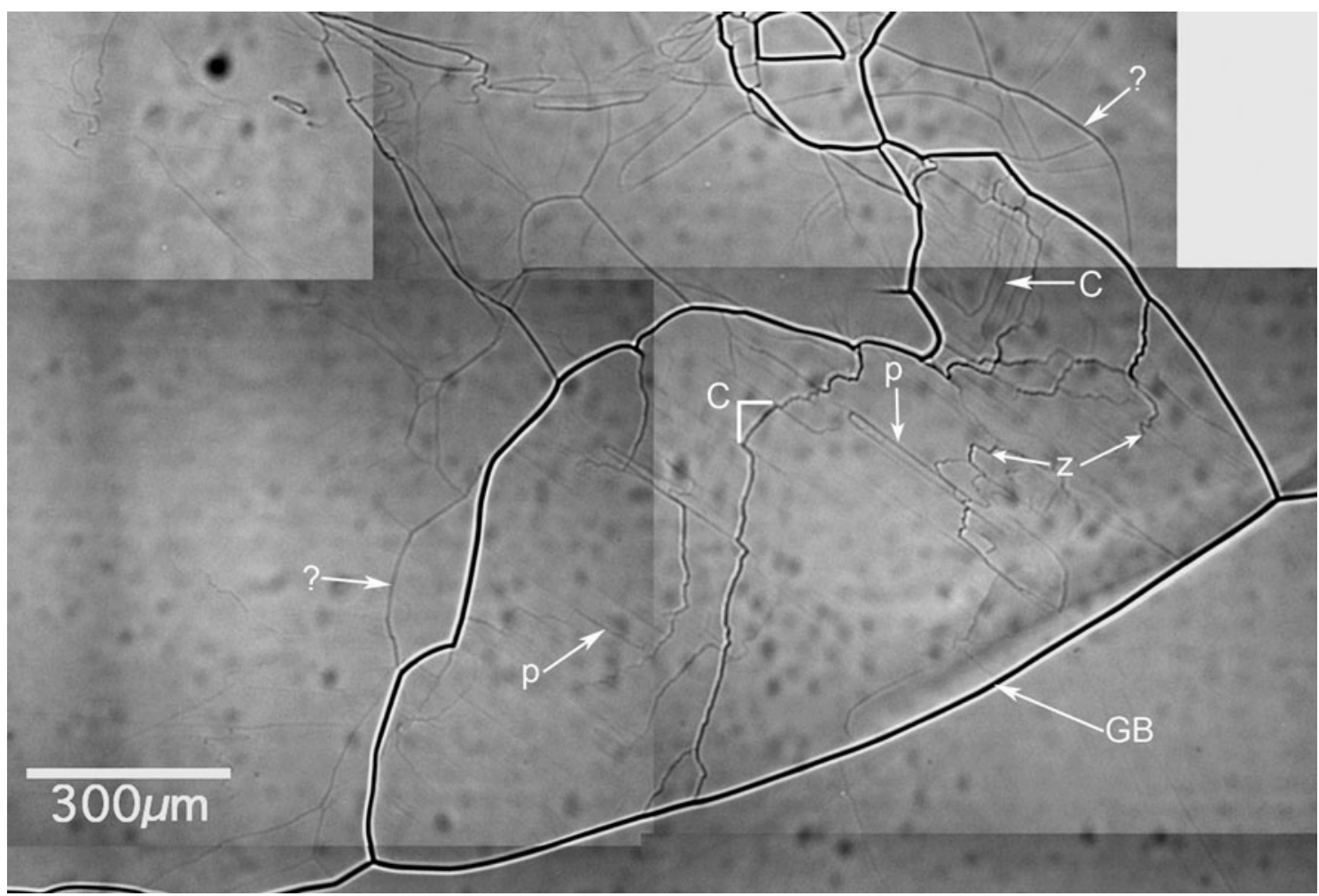

Fig. 7. Types of subgrain boundaries in a vertical section $\left(-4.8^{\circ} \mathrm{C}, 0.52 \mathrm{MPa}, 8.56 \%\right.$ total strain). $\mathrm{GB}$ - grain boundary; $p-$ parallel subgrain boundary; ? - not yet classified subgrain boundary; c - classical polygonization type subgrain boundary.

three subgrain-boundary types: parallel subgrain boundaries are not only exactly parallel to others in the swarm, but are also parallel to the trace of the basal plane (type $\mathrm{p}-$ parallel); zigzag or step-shaped subgrain boundaries usually run in one reticule direction parallel and in the other at a high angle to the basal plane (type z - zigzag); regular, more-or-less straight subgrain boundaries with the classical polygonization orientation (perpendicular to the basal plane) have also been observed (c - classical polygonization type), but almost always change into the zigzag type at one end (Figs 7 and 8). Bowed subgrain boundaries and those without any distinct shape usually do not seem to correspond with the crystal orientation and cannot be classified.

Due to the striking and easily recognizable nature of parallel subgrain boundaries, statistics on their occurrence have been calculated (Fig. 4d). The fraction of the length of parallel subgrain boundaries over total subgrain boundaries, and the variability, is highest in undeformed samples, because the few subgrain boundaries occurring in initial samples are often parallel. In slightly deformed samples (up to $1 \%$ strain) the parallel type represents $\sim 20-30 \%$ of the total subgrain-boundary length, but for strains above $2 \%$ this frequency decreases rapidly to only several per cent.

\section{Distribution of subgrain boundaries within grains}

Subgrain boundaries are not randomly distributed within the grain. They accumulate along grain boundaries, i.e. they usually start somewhere along a grain boundary and fade out towards the crystal core. However, the distribution along the grain boundaries is not homogeneous. Accumulation of subgrain boundaries in some regions of grains, preferentially at edges or necks, has been observed (Fig. 9). The heterogeneous distribution can be described as a 'core and mantle' structure (Kipfstuhl and others, 2006); a mantle describing the rim of the crystal with high subgrain-boundary density and the core defined by low subgrain-boundary density in the middle of a grain. This description holds for most grains.

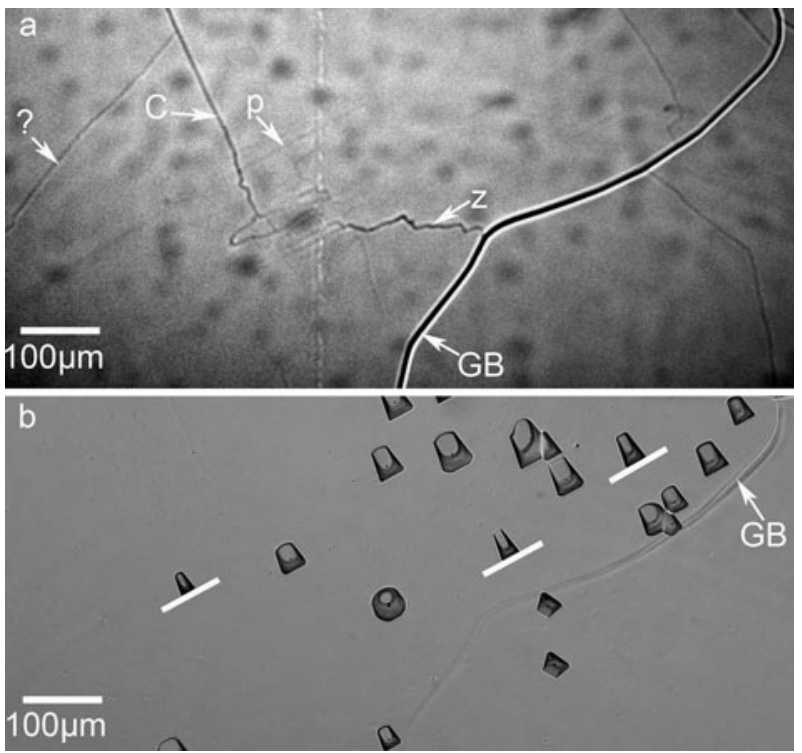

Fig. 8. Combination of microstructure mapping and etch-pit method. Example of vertical section $\left(-4.8^{\circ} \mathrm{C}, 0.35 \mathrm{MPa}, 1.22 \%\right.$ strain). (a) Sublimated surface showing grain boundaries (GB) and different types of subgrain boundaries ( $p$ - parallel; $z$ - zigzag; c - classical polygonization type; ? - not identified). (b) Etch pits produced on same sector as (a). Short white bars indicate trace of basal plane in cutting surface according to etch-pit shape. Note: parallel type is parallel to basal plane trace; classical polygonization type is perpendicular to basal plane trace. 

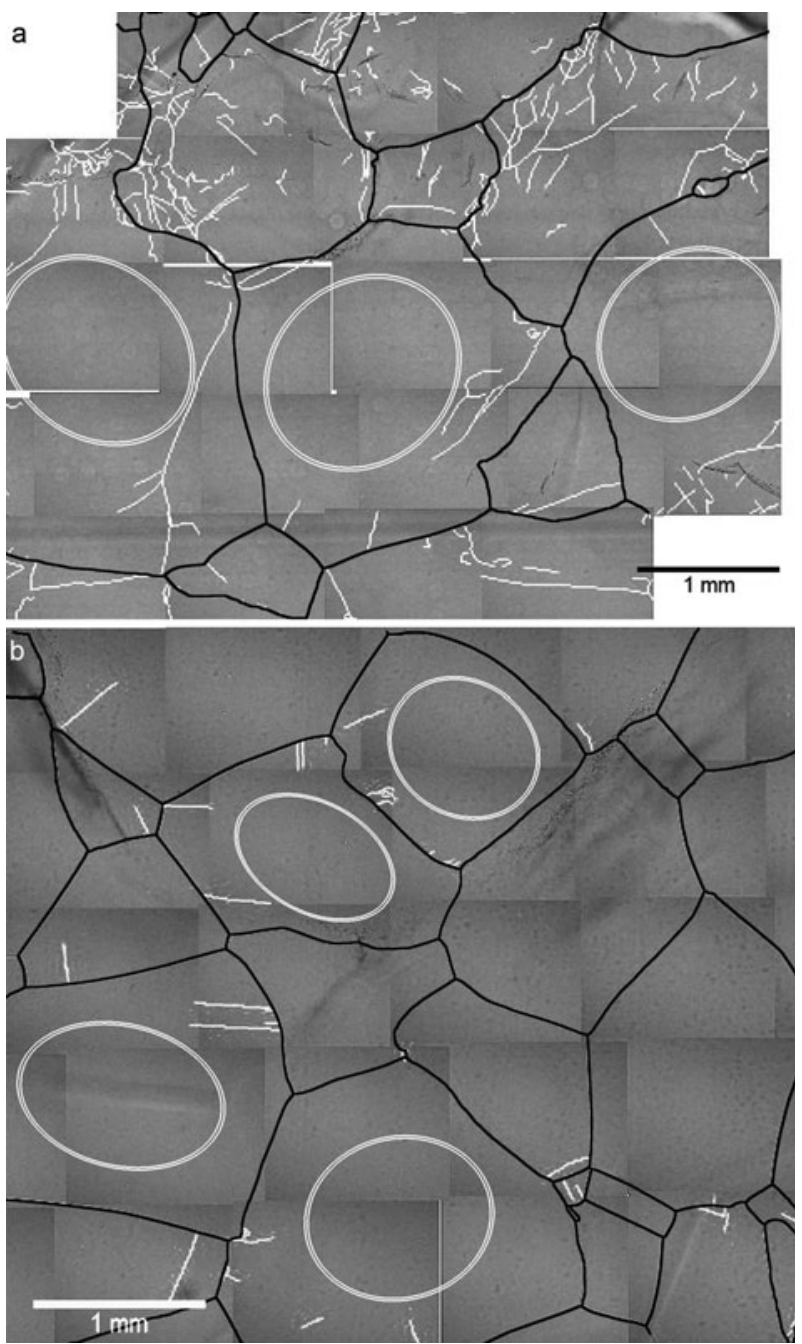

Fig. 9. Distribution of subgrain boundaries (marked as lines). Most subgrain boundaries are attached or close to a grain boundary (black), forming a subgrain-boundary-free core (approximately indicated by ellipses), which is not sharply defined. (a) Horizontal section $\left(-4.8^{\circ} \mathrm{C}, 0.35 \mathrm{MPa}, 1.22 \%\right.$ total strain). (b) Horizontal section $\left(-4.9^{\circ} \mathrm{C}, 0.35 \mathrm{MPa}, 0.44 \%\right.$ total strain). Note: Distribution inside grain is highly heterogeneous, e.g. areas of higher subgrainboundary density (top of (a)).

Detailed measurements of subgrain-boundary density give values two to five times higher near to grain boundaries $\left(1-36 \mathrm{~mm}^{-1}\right.$; see Fig. 10), compared to the mean subgrainboundary density ( 3 and $6 \mathrm{~mm}^{-1}$; see Fig. 4c). This difference clearly indicates the heterogeneity of the subgrain-boundary distribution within grains. Detailed subgrain-boundary density was measured choosing curved grain boundaries. An additional observation was that the majority of curved grain boundaries have more subgrain boundaries on their convex side than on the concave side (Fig. 10b).

\section{INTERPRETATION AND DISCUSSION \\ Creep behaviour and substructure evolution}

At $\sim 2 \%$ strain (i.e. at minimum strain rate; Fig. 2) a steady value of mean subgrain-boundary density is reached (Fig. 4c). This finding indicates that strain hardening during primary creep corresponds to the evolution of the substructure of the crystal. Duval and others (1983) suggest the
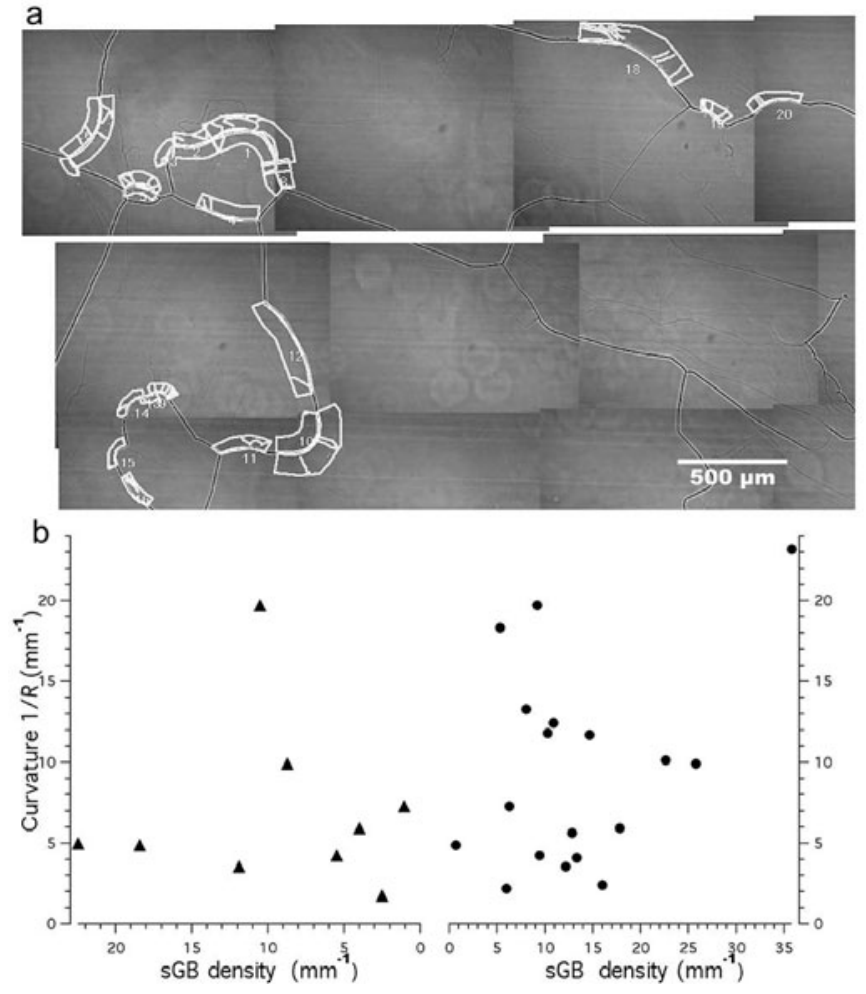

Fig. 10. Subgrain-boundary density in the vicinity of curved grain boundaries $\left(-4.8^{\circ} \mathrm{C}, 0.52 \mathrm{MPa}, 8.56 \%\right.$ total strain). (a) Schematic showing how subgrain-boundary density was determined with measured areas, subgrain boundaries and curvatures. Numbers refer to the measurement. (b) Curvatures against subgrain-boundary densities. Areas on convex $(\bullet)$ and concave $(\boldsymbol{\Lambda})$ sides of the curve are shown separately.

decrease in creep rate during this stage is due to two different hardening processes: kinematic hardening and isotropic hardening. Kinematic hardening is evidenced by partly recoverable deformation during transient strain, due to non-uniform distribution of long-range internal stresses caused by different orientations of grains which favour or hinder basal slip in the individual grain.

Isotropic hardening is the non-reversible component of strain during transient creep ascribed by Duval and others (1983) to a period of zero strain rate during stress-drop experiments. The processes leading to isotropic strain hardening can be observed directly using subgrain-boundary density data. Dislocations which accomplish plastic creep (e.g. Duval and others, 2000; Montagnat and Duval, 2000, 2004) form dislocation walls and subgrain boundaries. The synchrony of achievement of minimum strain rate and steady subgrain-boundary density suggests that the cause for this part of strain hardening is the production of obstacles which hinder the motion of dislocations. The most common obstacles for dislocations in ice are dislocation walls and subgrain boundaries. As the production of such obstacles and the prevention of dislocation motion is increased, the deformation rate keeps decreasing until a steady density of obstacles is reached. This coincides with attaining the maximum value of the subgrain-boundary density.

When an obstacle is encountered, dislocations cannot move freely and stress must accumulate. It is plausible that this stress accumulation leads to locally increased dislocation production due to sources for dislocations at nodes or 


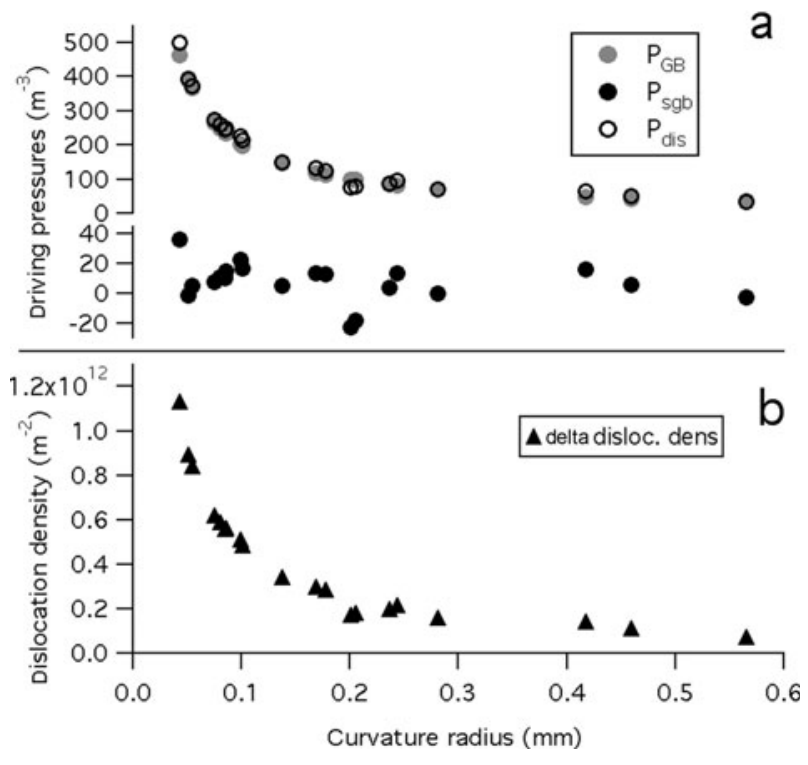

Fig. 11. (a) Driving pressures on the convex sides of the curved grain boundaries calculated from curvature radii $\left(P_{\mathrm{GB}}\right)$ and subgrain-boundary density measurements $\left(P_{\mathrm{SGB}}\right)$ (Fig. 10). Minimum driving pressures by dislocations to keep these curvature radii are also given $\left(P_{\text {dis }}\right)$. Note the second $y$ axis with a larger scale for $\left(P_{\mathrm{SGB}}\right)$. (b) Minimum dislocation density excess which has to be larger on the convex side for the radius of curvature to remain stable, estimated from minimum driving pressures by dislocations.

steps formed by obstacles in the glide plane (Ahmad and others, 1986) and increased subgrain-boundary formation by dislocation pile-up. Three observations indeed reveal significant deformation inhomogeneity inside the sections and even inside the grains: (i) the high variability of single measurements (bars in Fig. 4c); (ii) the qualitatively observable heterogeneous distribution of subgrain boundaries (Fig. 9); and (iii) the difference between mean subgrainboundary densities (up to $\sim 5.5 \mathrm{~mm}^{-1}$; see Fig. $4 \mathrm{c}$ ) and the locally measured subgrain-boundary density (up to $36 \mathrm{~mm}^{-1}$; see Fig. 10). Not only is the internal stress of the non-uniform state due to resistance to creep between basal and other planes (Duval and others, 1983), but also the deformation within the grains is not homogeneous. This finding is in general accordance with strain gradients in ice described by Montagnat and others (2003) and interpreted, following Ashby (1970), as being associated with the storage of geometrically necessary dislocations.

Subgrain-boundary obstacles lead to a higher strainenergy accumulation than expected under the assumption that dislocations cross the whole grain, reach grain boundaries and are absorbed by them (Pimienta and Duval, 1987). This non-uniform state of strain energy within grains can be studied in the vicinity of grain-boundary curves. These areas are chosen because the existence of 'bulges' indicates a difference in energy across the boundary (e.g. Duval and others, 1983; Barber, 1990).

The energy change, $\Delta E$, across a migrating grain boundary is given by

$$
\Delta E=\Delta E_{\mathrm{GB}}+\Delta E_{\mathrm{SGB}}+\Delta E_{\mathrm{dis}}
$$

where $\Delta E_{\mathrm{GB}}$ is due to grain-boundary area change, $\Delta E_{\mathrm{sGB}}$ is due to subgrain-boundary area change and $\Delta E_{\mathrm{dis}}$ is a consequence of removal of dislocations by the passage of grain boundaries.

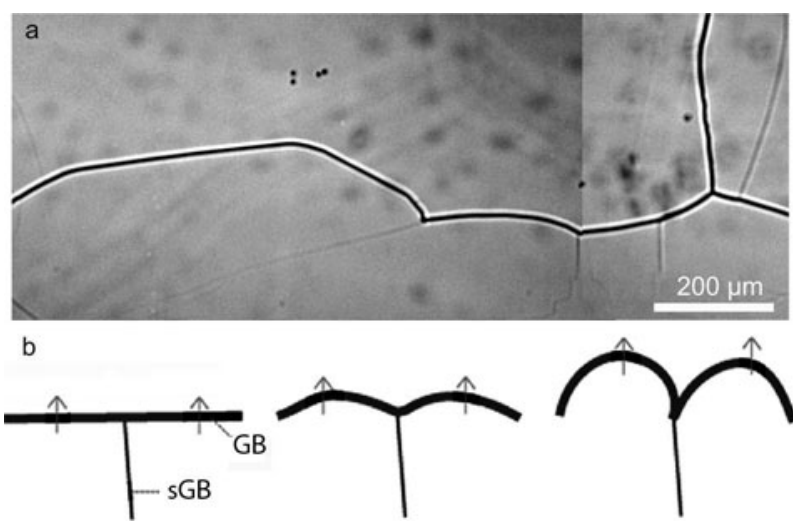

Fig. 12. Extensive interaction of subgrain boundaries with grain boundaries. (a) The geometry indicates pinning of a moving grain boundary by the subgrain boundary $\left(-4.5^{\circ} \mathrm{C}, 0.35 \mathrm{MPa}, 2.8 \%\right.$ total strain). (b) Conceptual model; the grain boundary is moving towards the top of the picture (arrows indicate direction of movement) and the subgrain boundary pins it where they meet, in a similar way to particle-pinning of grain boundaries.

This energy change exerts a driving stress, $P$, on the grain boundary:

$$
P= \pm P_{\mathrm{GB}}+P_{\mathrm{sGB}}+P_{\mathrm{dis}}
$$

The driving pressure on the convex side of the curved grain boundary, $P_{\mathrm{GB}}=\left(2 \gamma_{\mathrm{GB}}\right) / R$, is acting against motion to the convex side and is therefore subtracted. The grain-boundary energy, $\gamma_{\mathrm{GB}}$, is $\sim 10^{-2} \mathrm{~J} \mathrm{~m}^{-2}\left(4.2 \times 10^{-2} \mathrm{~J} \mathrm{~m}^{-2}\right.$ : Petrenko and Whitworth, 1999; $6.5 \times 10^{-2} \mathrm{~J} \mathrm{~m}^{-2}$ : Ketcham and Hobbs, 1969; Hobbs, 1974). The curvature radii, $R(\sim 0.05-0.3 \mathrm{~mm}$; Fig. 10), are significantly smaller than values usually considered, which use mean grain size for such estimations.

Driving stress due to subgrain-boundary removal by sweep of grain boundaries is $P_{\mathrm{sGB}}=\gamma_{\mathrm{sGB}} \Delta \rho_{\mathrm{sGB}}$, with $\gamma_{\mathrm{sGB}}$ being the subgrain-boundary energy $\left(\sim \gamma_{\mathrm{GB}} / 10\right.$; Humphreys and Hatherly, 2004) and $\gamma_{\mathrm{sGB}}$ the subgrain-boundary density difference across the grain boundary.

$P_{\mathrm{GB}}$ and $P_{\mathrm{SGB}}$ can be calculated using data shown in Figure 10. Values for $P_{\mathrm{sGB}}$ (Fig. 11a) are negative or positive depending on the subgrain boundary frequency on the convex and concave sides of the grain boundary. Although $P_{\mathrm{SGB}}$ is usually positive, $P_{\mathrm{GB}}$ reaches much higher values (by two orders of magnitude) due to the very small curvature radii compared to the maxima of $P_{\mathrm{SGB}}$. This estimate shows that the internal strain energy contributed by the subgrain boundaries is not enough to produce the observed curvature radii. Grain-boundary motion is not affected by subgrain boundaries themselves, although frequently observed pinning of grain boundaries at intersections with subgrain boundaries (Fig. 12) indicates there are exceptions. As dislocations collected in subgrain boundaries or dislocation walls do not provide enough internal strain energy to produce the observed curvatures, internal energy exerted by more randomly distributed dislocations must be operating (also estimated in Fig. 11a). Thus subgrain-boundary occurrence indicates a higher dislocation density accumulated around them by acting as obstacles.

The driving pressure caused by removal of dislocations other than those which comprise dislocation walls or subgrain boundaries is $P_{\text {dis }}=0.5 \Delta \rho_{\text {dis }} G b^{2}$ (e.g. Duval, 1985; Humphreys and Hatherly, 2004), where $\Delta \rho_{\text {dis }}$ is the 
minimum dislocation density excess which has to be larger on the convex side for the radius of curvature to remain stable, $G$ is the shear modulus $\left(35.2 \times 10^{8} \mathrm{~N} \mathrm{~m}^{-2}\right.$; Petrenko and Whitworth, 1999) and $b$ is the Burgers vector of a perfect dislocation in the basal plane ( $\sim 0.5 \mathrm{~nm}$; Hondoh, 2000). Considering motion of the grain boundary to the convex side as indicated by the bulging, $P$ in Equation (2) must be positive $(P \geq 0) . \Delta \rho_{\text {dis }}$ can then be estimated (Fig. 11b). Minimum dislocation densities reach values of $10^{12} \mathrm{~m}^{-2}$, one to two orders of magnitude higher than previously estimated (Duval, 1985) or modelled (Montagnat and Duval, 2000) for bulk ice samples. Dislocation densities locally increased by subgrain boundaries acting as obstacles can produce enough internal energy to initiate strain-induced grainboundary migration during the early stages of creep.

\section{Grain-growth reduction during deformation}

The parabolic growth law which describes the grain growth of ice crystals in firn (Gow, 1969), and which is widely applied to ice in ice sheets,

$$
A=D_{0}^{2}+k t,
$$

can be applied to grain-growth experiments with no applied stress $\left(k \approx 5.1 \times 10^{2} \mathrm{~mm}^{2} \mathrm{a}^{-1} ;\right.$ Fig. 3$)$. The growth rate, $k$, is temperature-dependent.

Grain-size data from creep experiments indicate that grains grow during deformation, but growth is significantly slower than during grain growth with no loading at the same temperature (Fig. 3). We observe an influence of temperature on grain-size evolution during primary/secondary creep (Fig. 3). Jacka and Li (1994) suggest the dependence of grainsize evolution on stress during steady-state tertiary creep is largely independent of temperature. Although creep clearly reduces grain growth during creep tests, we cannot find an explicit dependence on stress. An explanation might be that due to the fact that our experiments do not represent the tertiary creep stage, the measured grain sizes can be regarded as intermediate stages moving towards the steady-state crystal size described by Jacka and Li (1994). Creep experiments at conditions chosen here indicate both temperature and stress dependence of grain-size evolution. This suggests that primary and secondary creep provide a transition between the dependence of grain size on temperature and its dependence on stress.

During experiments which take place at annealing conditions, static grain growth influences grain size and grains can grow according to the grain-growth constant, $k$, for a given temperature following Equation (4). Additional processes affecting grain size take place during creep (Gow and Williamson, 1976). Whether these effects compete with or support normal grain growth probably depends on initial grain size, and possibly on other factors such as stress and, eventually, strain rate. Our experimental conditions enable processes which reduce grain-growth rates. As grain size moves towards a stress-dependent tertiary steady-state value, the reducing effect of deformation on grain growth is expected to be small with small stress (fig. 3 in Jacka and $\mathrm{Li}, 1994)$. Experiments conducted at 0.18 MPa clearly show the reduction of grain growth by creep (Fig. 3). However, further experiments are required to clarify whether a threshold stress is needed for the competing processes in grain growth at very small stresses (i.e. $<0.18 \mathrm{MPa}$ ).

In the following we consider three micro-processes that could be responsible for the grain-growth reduction:
(1) effects of soluble and insoluble impurities on mobility of grain boundaries and driving stresses; (2) splitting of grains by subgrain-rotation recrystallization (polygonization); and (3) migration recrystallization by locally very high grainboundary migration rates and/or by nucleation of new strainfree grains.

(1) The inhibition of grain growth by impurities and particles that is often seen (Alley and others, 1986; Thorsteinsson and others, 1995) can be excluded here, because purewater ice has been used to produce the samples. Therefore the grain-growth reduction, observed in these experiments, must be caused by deformation, even though only low total strains are reached.

(2) Although significant fabric change and intense grain rotation are not expected at these low strains (Azuma and Higashi, 1985), subgrain-boundary formation takes place; it is the first stage of splitting of grains by subgrain-rotation recrystallization. Unfortunately fabric data could not be obtained systematically due to the small sample size with relatively small crystal numbers per thin section after tests and problems with application of the etch-pit method. However, the extent to which subgrain boundaries contribute to grain-growth reduction depends on the development into high-angle grain boundaries. Further rotation of subgrains and therefore further deformation is needed. Additionally, removal of subgrain boundaries by grain-boundary migration needs to be considered. Providing a first stage of polygonization, subgrain boundaries contribute to grain-growth reduction. However, a direct correlation between higher subgrain-boundary density and smaller grain size during or after deformation cannot be shown.

(3) Migration recrystallization is described typically as the nucleation of new strain-free grains and the fast migration of grain boundaries (e.g. Duval and Castelnau, 1995), including two phenomena (strain-induced grainboundary migration (SIGBM) and recrystallization with nucleation) whose main characteristics are alike in that internal strain energy and relatively high temperatures are needed. Nucleation easily decelerates grain growth by production of small grains. However, this explanation is unlikely because true nucleation textures or grain nucleation near grain boundaries, which are visible in high-resolution microstructure maps of sublimation features, are not observed in our experiments. The spontaneous nucleation process is difficult to achieve, requiring very high internal strain energies and high temperatures and, possibly, preferably oriented nucleation seeds. If one of these conditions is not adequately fulfilled, dynamic recrystallization always starts with SIGBM. Although usually described as causing high mean grain size due to the very high grain-boundary migration rate, SIGBM can reduce grain growth. SIGBM is evidenced by irregular grains (Fig. 5) with curves of grain boundaries producing interlocking textures (Duval and Castelnau, 1995; Goldsby and Kohlstedt, 2002). The bulging grain-boundary curves can be cut off from the parent grain by further grain-boundary motion, to build a new, small grain with a similar orientation to the parent (Humphreys and Hatherly, 2004, p. 251). Additionally, SIGBM can lead to apparent grain-growth reduction by three-dimensional duplication effects 
(studied in detail by Nishida and Narita, 1996) emerging only with interlocking textures: a single grain appears plurally in one section due to its multiple protuberances. It is inevitably counted and measured as two or more grains and therefore significantly decreases the measured mean grain size (also discussed by Gow, 1969; Alley and Woods, 1996). The occurrence of SIGBM is measured in creep samples using the perimeter ratio (Fig. 4b) and has been shown by estimates of local dislocation densities and observations of bulging grain boundaries. Irregularity is dependent on strain and indicates that the contribution of SIGBM to the deceleration of grain growth during deformation is important in these strain regimes.

\section{Implications for subgrain-boundary-formation processes}

It is known from other materials that the orientation of subgrain boundaries depends on the orientation of slip systems of dislocations accumulating in the grain (Trépied and others, 1980). As the dominant slip system in ice lies in the basal plane and other slip systems contribute much less to ice deformation (Hondoh, 2000), the different orientations and arrangements of subgrain boundaries give insights into basic considerations about how they are formed. Clearly these thoughts need to be inspected in more detail using full crystal orientation measurements, which are now becoming available (Montagnat and others, 2003; Miyamoto and others, 2005; Obbard and others, 2006b).

The type-c subgrain boundary (straight and basal plane orthogonal) can be explained by considering the classical, and so far only, formation process described in ice (Nakaya, 1958). A tilt boundary is built by pile-up and alignment of edge dislocations gliding on the basal plane during bending of the crystal.

Type-p subgrain boundaries (regular, straight and parallel to the basal plane) cannot be formed by bending of basal planes, but might be explained by analogy with the tilt boundary, i.e. as pile-up and accumulation of screw dislocations (Weertman and Weertman, 1992). The occurrence of this dislocation type in ice was shown by Montagnat and others (2003). A second possible interpretation for p-type subgrain boundaries might be micro-shear zones, which have been observed by Bons and Jessell (1999) in a rock-analogue material. In shear zones (of micrometres to kilometres) observed in rocks, a distinct package of material undertakes a high portion of the total strain of the bulk sample. In contrast to normal slip on basal planes accomplished by dislocations, a wider region of atomic layers consisting of several tens of layers is deformed while the bulk above and below the shear zone remains relatively undeformed. In our experimentally deformed samples, this type of subgrain boundary is quite unlikely, because a distinct grain geometry is needed for micro-shear zones (Bons and Jessell, 1999). However it has been observed in Antarctic ice (S. H. Faria and others, http://www.mis.mpg.de/ preprints/2006/prepr2006_33.html).

Type-z subgrain boundaries (zigzag or step-like) probably consist of tilt boundaries formed by edge dislocations on basal and non-basal planes. As most grains are not oriented to preferably build one type of dislocation, they probably form several dislocation types which align to type-z subgrain boundaries. However, motion of dislocations in many directions (climb and glide) is necessary to obtain sections of relatively pure tilt or twist boundary. Preliminary X-ray Laue measurements confirm the existence of tilt and twist boundaries (personal communication from A. Miyamoto, 2007).

The rapidly decreasing frequency of type-p subgrain boundaries (Fig. 4d) shows that they are not produced under our conditions and suggests that it is the other types ( $c$ and $z$ ) that are produced in our experiments.

\section{Outlook: similarity of high- and low-stress microstructures}

Experiments have been conducted at stresses between 0.18 and $0.52 \mathrm{MPa}$. Compared with the polar ice sheets, where driving stresses are typically $<0.1 \mathrm{MPa}$, measured deformation rates are very high. It is interesting, then, that observed ice substructures are very similar in deformed artificial ice and ice from deep Antarctic ice cores, especially as the experiments reached only secondary creep whereas polar ice deforms, predominantly, in near-steady-state tertiary creep.

As mentioned above, the typical shapes and arrangements of subgrain-boundary types found in the experimentally deformed ice have been characterized in an Antarctic ice core (EDML; data will be presented elsewhere). Due to this observation and the high mechanical anisotropy of ice it can be assumed that these structures are, indeed, characteristic traces of deformation processes displaying the material's response to creep. The similarity between the subgrainboundary types can be explained by the preponderance of internal dislocation slip for the deformation of polar and artificial ice (Duval and others, 1983; Montagnat and Duval, 2000). A difference might be found in the fraction of the different subgrain-boundary types. In our experiments the fraction of parallel-type subgrain boundaries decreases rapidly with strain, yet this is the most common kind found throughout the deep ice core. This finding suggests further studies are necessary to learn about the activity of dislocation types in low- and high-stress regimes. Furthermore, distributions of subgrain boundaries inside grains are very similar. In both cases, substructures are observed close to grain boundaries forming a 'core and mantle' structure. The accumulation at protruding parts of grains strikingly indicates that strain accumulation is the rule rather than the exception in deforming ice in general. The preponderance of subgrain boundaries on the convex side of grainboundary curves (Fig. 10) has also been observed in ice sheets, suggesting that local dislocation-density peaks can also occur in ice at low stresses. Most surprising is that mean subgrain-boundary density is of the same order in high-stress experiments $\left(\sim 4 \mathrm{~mm}^{-1}\right.$; see Fig. $\left.4 \mathrm{c}\right)$ and in the EDML ice core $\left(\sim 2 \mathrm{~mm}^{-1}\right)$. The slightly lower values in ice deformed at low stresses can be explained by recovery processes which can act with the prolonged duration of creep.

Alongside other similarities in substructure observed in experiments and in ice cores, the evolution of grain growth and especially its dependence on creep should be investigated. This requires further examination of strain-rate effects, impurity effects and other possible factors. In experiments the grain-growth reduction is already significant at low strains. At the higher strains in polar ice it is possible that strain inhomogeneities in layers of the ice sheet lead to significant differences in grain size; further work is required to clarify this. However, deformation needs to be considered as a possible cause for grain-size variation in ice cores. 


\section{CONCLUSIONS}

Observations of microstructure evolution during creep experiments have been presented which provide new information about deformation processes at the subgrain scale.

Deformation can significantly reduce grain growth without the presence of solutes or particles. Even at low strains, $<10 \%$, subgrain-rotation recrystallization and strain-induced grain-boundary migration lead to less grain growth than under unstrained conditions. Local strain inhomogeneities in polar ice sheets have to be considered when studying sudden grain-size changes in ice cores.

The creep experiments demonstrate the connection between isotropic hardening during primary creep and substructure evolution. The hardening is due to the production and interaction of dislocation walls and subgrain boundaries which act as obstacles for dislocation movement. Strain heterogeneities observed inside grains lead to locally high dislocation densities $\left(10^{12} \mathrm{~m}^{-2}\right)$, which can cause SIGBM. Similarities in substructure observations indicate similar processes in polar ice.

Different types of subgrain boundaries indicate several formation processes in which several types of dislocations must be involved. The described substructures are indicative of the deformation of ice because they have been observed in artificial and polar ice due to the preponderance of intracrystalline slip.

\section{ACKNOWLEDGEMENTS}

This work was supported by a Grant-in Aid for Science Research (No. 16104006) from the Ministry of Education, Culture, Sports, Science and Technology, Japan. Travel funding was received from the German Academic Exchange Service (DAAD). We thank T. H. Jacka for inspiring discussions, laboratory members (M. Takada, A. Shigekuni, Y. Oba, T. Kokure, T. Nakamura, K. Oba, K. Anno, H. Kobayashi and many others) who helped in many ways and two anonymous reviewers for helpful comments.

\section{REFERENCES}

Ahmad, S., M. Ohtomo and R.W. Whitworth. 1986. Observation of a dislocation source in ice by synchrotron radiation $\mathrm{X}$-ray topography. Nature, 319(6055), 659-660.

Alley, R.B. and G.A. Woods. 1996. Impurity influence on normal grain growth in the GISP2 ice core, Greenland. J. Glaciol., 42(141), 255-260.

Alley, R.B., J.H. Perepezko and C.R. Bentley. 1986. Grain growth in polar ice: I. Theory. J. Glaciol., 32(112), 415-424.

Ashby, M.F. 1970. The deformation of plastically non-homogeneous materials. Philos. Mag., 21(8), 399-424.

Azuma, N. and A. Higashi. 1985. Formation processes of ice fabric pattern in ice sheets. Ann. Glaciol., 6, 130-134.

Barber, D.J. 1990. Regimes of plastic deformation processes and microstructures: an overview. In Barber, D.J. and P.G. Meredith, eds. Deformation processes in minerals, ceramics and rocks. London, Unwin Hyman, 138-178.

Bons, P.D. and M.W. Jessell. 1999. Micro-shear zones in experimentally deformed octachloropropane. J. Struct. Geol., 21(3), 323-334.

Budd, W.F. and T.H. Jacka. 1989. A review of ice rheology for ice sheet modelling. Cold Reg. Sci. Technol., 16(2), 107-144.

Duval, P. 1985. Grain growth and mechanical behaviour of polar ice. Ann. Glaciol., 6, 79-82.

Duval, P. and O. Castelnau. 1995. Dynamic recrystallization of ice in polar ice sheets. J. Phys. IV [Paris], 5, 197-205. (Supplément au 3.)
Duval, P. and H.I. Gac. 1980. Does the permanent creep-rate of polycrystalline ice increase with crystal size? J. Glaciol., 25(91), 151-157.

Duval, P. and C. Lorius. 1980. Crystal size and climatic record down to the last ice age from Antarctic ice. Earth Planet. Sci. Lett., 48(1), 59-64.

Duval, P., M.F. Ashby and I. Anderman. 1983. Rate-controlling processes in the creep of polycrystalline ice. J. Phys. Chem., 87(21), 4066-4074.

Duval, P., L. Arnaud, O. Brissaud, M. Montagnat and S. de la Chapelle. 2000. Deformation and recrystallization processes of ice from polar ice sheets. Ann. Glaciol., 30, 83-87.

Gay, M. and J. Weiss. 1999. Automatic reconstruction of polycrystalline ice microstructure from image analysis: application to the EPICA ice core at Dome Concordia, Antarctica. J. Glaciol., 45(151), 547-554.

Glen, J.W. 1955. The creep of polycrystalline ice. Proc. R. Soc. London, Ser. A., 228(1175), 519-538.

Goldsby, D.L. and D.L. Kohlstedt. 1997. Grain boundary sliding in fine-grained ice I. Scripta Mater., 37(9), 1399-1406.

Goldsby, D.L. and D.L. Kohlstedt. 2002. Reply to comment by P. Duval and M. Montagnat on 'Superplastic deformation of ice: experimental observations'. J. Geophys. Res., 107(B11). (10.1029/2002JB001842.)

Gow, A.J. 1969. On the rates of growth of grains and crystals in South Polar firn. J. Glaciol., 8(53), 241-252.

Gow, A.J. and Williamson, T. 1976. Rheological implications of the internal structure and crystal fabrics of the West Antarctic ice sheet as revealed by deep core drilling at Byrd Station. CRREL Rep. 76, 1665-1677.

Hobbs, P.V. 1974. Ice physics. Oxford, etc., Clarendon Press.

Hondoh, T. 2000. Nature and behavior of dislocations in ice. In Hondoh, T., ed. Physics of ice core records. Sapporo, Hokkaido University Press, 3-24.

Hooke, R.LeB. 2005. Principles of glacier mechanics. Second edition. Upper Saddle River, NJ, Prentice Hall.

Humphreys, F.J. and M. Hatherly. 2004. Recrystallization and related annealing phenomena. Second edition. Oxford, etc., Pergamon Press.

Jacka, T.H. 1984. The time and strain required for development of minimum strain rates in ice. Cold Reg. Sci. Technol., 8(3), 261-268.

Jacka, T.H. and J. Li. 1994. The steady-state crystal size of deforming ice. Ann. Glaciol., 20, 13-18.

Jacka, T.H. and R.C. Lile. 1984. Sample preparation techniques and compression apparatus for ice flow studies. Cold Reg. Sci. Technol., 8(3), 235-240.

Ketcham, W.M. and P.V. Hobbs. 1969. An experimental determination of the surface energies of ice. Philos. Mag., 19(162), 1161-1173.

Kipfstuhl, S. and 6 others. 2006. Microstructure mapping: a new method for imaging deformation-induced microstructural features of ice on the grain scale. J. Glaciol., 52(178), 398-406.

Miyamoto, A., H. Shoji, A. Hori, T. Hondoh, H. Clausen and O. Watanabe. 2005. Ice fabric evolution process understood from anisotropic distribution of a-axis orientation on the GRIP (Greenland) ice core. Ann. Glaciol., 42, 47-52.

Montagnat, M. and P. Duval. 2000. Rate controlling processes in the creep of polar ice: influence of grain boundary migration associated with recrystallization. Earth Planet. Sci. Lett., 183(1-2), 179-186.

Montagnat, M. and P. Duval. 2004. The viscoplastic behaviour of ice in polar ice sheets: experimental results and modelling. C. R. Phys., 5(7), 699-708.

Montagnat, M., P. Duval, P. Bastie and B. Hamelin. 2003. Strain gradients and geometrically necessary dislocations in deformed ice single crystals. Scripta Mater., 49(5), 411-415.

Mullins, W.W. 1957. Theory of thermal grooving. J. Appl. Phys., 28(3), 333-339. 
Nakaya, U. 1958. Mechanical properties of single crystals of ice. Part 1. Geometry of deformation. SIPRE Res. Rep. 28.

Nishida, K. and H. Narita. 1996. Three-dimensional observations of ice crystal characteristics in polar ice sheets. J. Geophys. Res., 101(D16), 21,311-21,317.

Nishimura, K. 2004. The effect of impurities on grain growth rate on ice of Antarctic ice cores. (Master's thesis, Nagaoka University of Technology.)

Obbard, R., I. Baker and D. Iliescu. 2006a. Correspondence. Grain boundary grooving in ice in a scanning electron microscope. J. Glaciol., 52(176), 169-172.

Obbard, R., I. Baker and K. Sieg. 2006b. Using electron backscatter diffraction patterns to examine recrystallization in polar ice sheets. J. Glaciol., 52(179), 546-557.

Passchier, C.W. and R.A.J. Trouw. 1996. Microtectonics. Berlin and Heidelberg, Springer-Verlag.

Paterson, W.S.B. 1994. The physics of glaciers. Third edition. Oxford, etc., Elsevier.
Petrenko, V.F. and R.W. Whitworth. 1999. Physics of ice. Oxford, etc., Oxford University Press.

Pimienta, P. and P. Duval. 1987. Rate controlling processes in the creep of polar glacier ice. J. Phys. [Paris], 48, Colloq. C1, 243248. (Supplément au 3.)

Saylor, D.M. and G.S. Rohrer. 1999. Measuring the influence of grain-boundary misorientation on thermal groove geometry in ceramic polycrystals. J. Am. Ceram. Soc., 82(6), 1529-1565.

Thorsteinsson, T., J. Kipfstuhl, H. Eicken, S.J. Johnsen and K. Fuhrer. 1995. Crystal size variations in Eemian-age ice from the GRIP ice core, central Greenland. Earth Planet. Sci. Lett., 131(3-4), 381-394.

Trépied, L., J.C. Doukhan and J. Paquet. 1980. Subgrain boundaries in quartz theoretical analysis and microscopic observations. Phys. Chem. Mineral., 5(3), 201-218.

Weertman, J. and J.R. Weertman. 1992. Elementary dislocation theory. Oxford, etc., Oxford University Press.

MS received 4 January 2007 and accepted in revised form 12 May 2007 